\title{
AC 2007-297: THE SOUND OF MATERIALS: CREATING EXCITEMENT FOR MATERIALS ENGINEERING AND SCIENCE IN ENGINEERING TECHNOLOGY PROGRAMS
}

\section{Kathleen Kitto, Western Washington University}

Kathleen L. Kitto is the Associate Dean for the new College of Sciences and Technology at Western Washington University. Previously, she was Associate Dean for the College of Arts and Sciences and served as Chair of Engineering Technology Department from 1995-2002. Since arriving at Western Washington University in 1988, her primary teaching assignments have been in the Manufacturing Engineering Technology program and in the development of the communication skills of engineering technology students; her research interests have been in the materials science of musical instruments, development of concurrent engineering curricula, development of devices for the differently-abled and in finite element analysis of complex components. She is keenly interested in enhancing the diversity of the students studying in the sciences, mathematics and technology. She received both her MS and BS degrees from the University of Montana/Montana Tech and previously worked for many years in industry primarily developing instrumentation systems and advanced materials. 


\title{
The Sound of Materials: Creating Excitement for Materials Engineering and Science in Engineering Technology Programs
}

\begin{abstract}
During the past four years the materials engineering aspects of musical instrument design have been incorporated into our Introductory Materials Engineering course to excite students about materials engineering and science and to help them understand various complex behaviors of materials, such as anisotropic properties or specific stiffness, through familiar, practical applications. The answer to a seemingly simple question about why a Stradivarius violin sounds the way it does is found more in complex materials properties than in many other basic design constraints such as geometry. Results from the initial assessment data show that the students enjoy materials engineering to a higher degree, are more involved in their own learning, and score higher, as a group, on certain classical examination questions. For example, a classic set of problems covers stress, strain, yield, and the elastic constant given load and elongation data. The new way to introduce these same concepts is to use tuning and the design process to select strings for a violin or a guitar. Music strings produce sounds because of their elastics constants, densities and composite structures. Violin strings, because they must follow bowing action, are composite structures that must damp signals, while guitar strings should resonate as long as possible. Another illustration is that students have a difficult time conceptually understanding that objects strain under load, but they do know that musical strings change pitch during tuning. Once the students understand the underlying concepts, they more easily make the transition to classical problems. In addition to enhancements in the course and improving test scores, this strategy has succeeded in building excitement for materials engineering within the program. For example, two students subsequently worked on independent study courses and created an all carbon-fiber composite violin, two students are working on creating new electric guitars, one student completed a senior project examining the dynamic mechanical properties of violin tone wood, and a new student research group was formed.

This paper describes the exercises and demonstrations that have been used in our Introductory Materials Engineering course that have stimulated enthusiasm for materials engineering and have contributed to measurable enhancements to the course. The paper also describes those activities that might be transferred to other types of institutions to accomplish materials awareness and excitement. Specific materials science properties as they relate to stringed instrument design are given so that others adapt them for their own use. In addition, this paper contains a comprehensive literature search of the materials science aspect of musical instrument design to make it easier for others to adapt the ideas presented in this paper.
\end{abstract}

\section{Introduction}

We have transformed our materials engineering course to include aspects of musical instrument design with the aim of exciting students about materials engineering and to help them conceptually understand complex behaviors of materials, such as anisotropic properties or specific stiffness, through a familiar and accessible context. The use of musical instrument engineering in class and in projects is part of a larger transformation of this course from a 
traditional lecture delivery format to an active, "learner centered" environment course. There were many reasons to invest the time and energy necessary to complete the many tasks needed for such a comprehensive transformation. First, recent research studies have shown that students do understand more about what they are studying if the course environment includes active and conceptual learning opportunities ${ }^{1-13}$. For example, the National Research Council (NRC) completed an in-depth study and reported on successful learning strategies ${ }^{1}$. This report and the work of others ${ }^{1-13}$ show that it is important to build upon the "conceptual and cultural knowledge that students bring with them to the classroom". $\quad$ Second, students often view Introductory Materials Engineering courses as difficult, abstract and less than exciting. It is usually the first course in which they must integrate what they have learned in their physics, chemistry, and mathematics courses to solve new and complex problems. A great deal of basic material must be covered in the course before students are able to comprehend the complex nature of material selection for engineering projects in service. It is easy to understand why students struggle since they often come to the course with little previous knowledge of key concepts such as dislocation motion, planar packing fractions, or metallic binary phase diagrams. It makes a great deal of sense that freshman or sophomore level students might be overwhelmed by the volume of information they must assimilate in this course for them to be successful. Finally, we know that student learning can also be improved when concepts are placed into a context in which the students have direct knowledge of, experience with, and interest in when they enter the class. Certainly, anyone who has walked across a college campus can attest to the large number of earbuds, iPods ${ }^{\circledR}$, and MP3 players in the everyday lives of students. Our experience has shown that most students can be engaged and even excited by attempts to answer the seemingly simple questions of musical instrument design with complex materials engineering and science concepts. Why do violins and guitars sound the way they do? What makes a Stradivarius violin so special?

The transformation of our Introduction to Materials Engineering course includes many other important components, such as case studies, other active learning exercises, and, perhaps, most importantly concept questions. These components have been described elsewhere and will not be described here ${ }^{14-15}$. The basic purpose then of this paper is to more fully describe how materials engineering for musical instrument design has been incorporated into the course and the conceptual reasons for doing so. For example, a classic set of problems encountered in an Introductory Materials Engineering course covers the calculation of tensile stresses for particular loads and geometries, calculating the elastic constant and yield from stress/strain data, and calculating elongation or strain under loads. A different way to introduce these concepts is using stringed instrument design for violins or guitars. Although students know that a stringed instrument is tuned by making the strings longer or shorter, a quick in-class demonstration reinforces the concept. Increasing the tension (usually in $\mathrm{N}$, a force in equations) on the string elongates the string and causes its frequency to increase. Of course, the tension (computed as stress) is related to the change in length (computed as strain) by the elastic constant. The context is new, but the basic concepts are the same as in classic problems. The discussion, design problems, and exercises (described later) that follow the demonstration covers every concept needed for students to successfully complete those classical problems. Once the students comprehend the basic concepts, completing classical problems is much easier for them, and, in fact, the initial assessment data does show improving scores on classic problems. In addition, the students are able to complete a much more difficult design problem by the end of the term. The 
underlying concepts are the same in both cases, but the students are more engaged and more excited about doing the problems in the context of musical instrument design. Once all the materials properties and design information is collected, it is also more interesting to introduce the concepts in a new context.

\section{Discussion}

In order to use musical instrument design and engineering in an Introductory Materials Engineering course, the students must be introduced to a few basic design concepts. First, the students should be reminded that musical instruments were created in a historical context with some instruments still evolving, while others such as the violin seems to have reached perfection in the Amati, Stradivari and Guarneri family workshops more than 300 years ago. Early instrument makers created their instruments from a limited selection set of materials (by today's standards) using mostly hand construction techniques. However, that historical context influenced the very essence of what is expected for that instrument. A violin must sound and look like a violin. There are expectations by musicians and audiences alike that all instruments should sound like they have historically sounded. Venturing too far away from our expectations for instrument geometry would be unacceptable as well. A design engineer then has more opportunity then to use new or alternative materials than the other basic design constraint geometry.

The students should also know the basics of how musical instruments produce sound. Stringed musical instruments produce sound because the player displaces a string from its neutral position by bowing, strumming, plucking or striking the string. The vibrations of the string are coupled to the resonating box of the instrument via the bridge. In instruments with reeds, such as clarinets or oboes, the player blows into the instrument and the vibrating reed sets the column of air within the tube in motion. In some cases, like in the trumpet, the vibrating lips of the player sets the air column in the tube in motion. A CD that contains the PowerPoint presentation of the basic design considerations of a stringed instrument will be available at the conference. Since the students have taken a basic physics sequence, they should be familiar with longitudinal and transverse standing waves. However, it is a good idea to remind them with a materials science based demonstration. In a solid, the velocity of longitudinal sound waves is controlled by two basic materials properties: the elastic constant and the density. Also, note that this demonstration will also provide an opportunity for the instructor to discuss the concept of specific stiffness or modulus and specific strength. In a rod, the longitudinal velocity of sound is:

$V=\sqrt{E / \rho} \quad$ where $\mathrm{E}$ is the Elastic Modulus and $\rho$ is the density of the rod

$f_{n}=\frac{n}{2 L} * \sqrt{E / \rho}$ where $f_{n}$ is the frequency of the mode and $\mathrm{L}$ is the length of the rod

Physicists have long used a demonstration called the "singing rod" to show students about longitudinal waves. However, it is even more useful in materials engineering to show students the effect and importance of $E / \rho$ as one of the most important design parameters used in materials selection for engineering applications. It is conceptually very important that students know that often it is not just the value of $E$ or tensile strength that determines the best material 
for a weight constrained application (aircraft or bicycles, for example). The "singing rod" is a memorable and amusing demonstration to introduce the concept and initial assessment data shows a more memorable way for them to still understand by the end of the term. This activity is easily accessible and transferable to other institutions. In fact, we have found students performing this demonstration to other students on campus after the in-class demo.

You can purchase "singing rods" in science supply stores. However, all you really need are solid or hollow rods made from particular materials. Physicists most often use an aluminum rod because they have a high Quality Factor (Q), which means aluminum has a sharp resonance which rings for a long time. Using more than one rod with each rod made from a different material is conceptually important in materials engineering. To produce the fundamental frequency in the rod, hold it at the center (a node), dust your fingers in a lot of powdered rosin or coat the rod with spray on sticky, and stroke the rod vigorously with your rosin coated fingers and thumb. Rods should be about $6 \mathrm{~mm}$ to $12 \mathrm{~mm}(1 / 4$ inch to $1 / 2 \mathrm{inch})$ in diameter and $1 \mathrm{~m}$ or 2 $\mathrm{m}$ in length. The sound the "singing rods" make is quite amazing and not forgettable. However, practice before you do the in-class demonstration as making the rod sing is not easy at first. Be careful to hold the rod at the nodes (center, $1 / 4$ length, etc.) and use a lot of rosin. Exciting the higher frequencies is more difficult as you have to use a fairly long rod and have the other positions marked in advance. Although you can excite the transverse frequency by striking a bar along its edge to demonstrate the difference in the waves, that velocity equation depends on the frequency; and that frequency equation includes additional geometric considerations [see equation (5)]. The transverse waves are obviously not harmonic, which is interesting, but this additional demonstration probably adds little to the points that are relevant to materials engineering, and could complicate the discussion unnecessarily.

The better way to illustrate transverse waves and more materials science is with vibrating strings. The frequency of a vibrating string is governed by an equation that is very useful to illustrate basic materials engineering. The velocity of a transverse wave in a vibrating string is:

$V=\sqrt{T / \mu} \quad$ where $\mathrm{T}$ is the Tension in $\mathrm{N}$ and $\mu$ is the mass/length in $\mathrm{kg} / \mathrm{m}$

The frequency of the fundamental and its harmonics (n) [for strings] is:

$f_{n}=\frac{n}{2 L} * \sqrt{T / \mu} \quad$ where $\mu=\pi \mathrm{r}^{2} \rho$ in $\mathrm{Kg} / \mathrm{m}$

The transverse vibration of a rod with free ends:

$f_{n}=\pi K m^{2} \frac{\sqrt{E / \rho}}{8 L^{2}} \quad$ where $\mathrm{K}$ is the radius of gyration, $\mathrm{m}=(2 \mathrm{n}+1)$

Given the information in Tables 1 through 5, it is very easy to create many different classic materials engineering problems that are placed in a new context. Again, because a great deal of basic design data is given in this paper, it would be relatively easy to use these activities at other 
institutions. For example, the students can calculated the stress in any string from the tension and diameter values, the elongation and strain at the design stress, calculate $\mathrm{V}, \mathrm{f}$ or $\mu$ from basic design data, and compare the design stresses to the breaking stress or yield strength of the material. An interesting calculation to highlight is the ever problematic violin E string or the limitations of using steel for piano strings. Strings should be as small as possible in diameter to reduce inharmonicity (the degree to which overtones are not precisely whole multiples of the fundamental frequency). Inharmonicity is high for steel because steel has a high $\mathrm{E}$ as the complex inharmonicity equation depends on the modulus of elasticity and the radius ${ }^{420}$. Using a general purpose music wire, ASTM $228^{21}$, to illustrate the importance of materials engineering to instrument design. Using the information provided in Tables 1 through 5, the calculated stress in a violin E string made from ASTM 228 could be as high as approximately $1650 \mathrm{MPa}$. The tensile strength of ASTM 228 in the range of the violin E string is approximately $2620-2650$ $\mathrm{MPa}^{21}$ and the yield strength range is 1590 to $2750 \mathrm{MPa}$ (depending on the wire diameter) ${ }^{27}$. The stress on the string is approximately $63 \%$ of the tensile strength which is in the $40 \%-75 \%$ range ${ }^{19}$ string designers often use for steel strings which explains the many broken strings as one strings the instrument or plays it too vigorously. Even though many high end players would prefer to use a gut E string, the materials properties of gut make it impractical to use and, thus, gut has gone out of use today. The load on a gut $\mathrm{E}$ string $(0.7 \mathrm{~mm})$ would be at $93 \%$ of its breaking strength ${ }^{49}$ ! No wonder, players tired of constantly changing gut violin $\mathrm{E}$ strings. Obviously, there is an opportunity to introduce the concept of setting safety factors to the students during this discussion. Given the E for ASTM 228 steel, $210 \mathrm{GPa}$, and the Poisson's ratio, 0.313 , the students can also calculate the resulting strains and elongations ${ }^{21}$. The students may also be given the design problem to calculate the string tensions and stresses that will produce the standard frequencies for various instruments.

Table 1. Violin Design Parameters Needed for Materials Engineering Exercises

\begin{tabular}{|l|l|l|l|l|}
\hline Violin & String & Measured & Manufacturer & Recommended \\
\hline Note & Hertz & Mass/Length g/m & 19 & Diameters mm \\
E5 & 659.26 & $0.381-0.443$ & $0.249-0.265$ & Tension N $^{16-17}$ \\
\hline A4 & 440.00 & $0.579-0.752$ & $0.452-0.701$ & $72.5-90.8$ \\
\hline D4 & 293.67 & $0.924-1.641$ & $0.671-0.914$ & $52.0-64.5$ \\
\hline G3 & 196.00 & $2.115-2.700$ & $0.790-0.833$ & $35.9-56.1$ \\
\hline
\end{tabular}

Table 2. Guitar Design Parameters Needed for Materials Engineering Exercises

\begin{tabular}{|l|l|l|l|l|}
\hline Guitar & String & Measured & Manufacturer & Recommended \\
Note & Hertz & $\begin{array}{l}\text { Mass/Length } \\
\mathbf{g} / \mathbf{m}^{19}\end{array}$ & Diameters $\mathbf{~ m m}^{18}$ & Tension $\mathbf{~}^{18}$ \\
\hline E4 & 329.63 & 0.417 & $0.36-0.699$ & $65.9-141.5$ \\
\hline B3 & 246.94 & 0.892 & $0.46-0.806$ & $49.8-131.3$ \\
\hline G3 & 196.00 & 1.03 & $0.69-1.01$ & $52.1-170.9$ \\
\hline D3 & 146.83 & 2.04 & $0.71-0.99$ & $65.9-201.2$ \\
\hline A2 & 110.00 & 3.45 & $0.84-1.24$ & $55.6-178.0$ \\
\hline E2 & 82.41 & 5.33 & $1.07-1.50$ & $58.7-143.3$ \\
\hline
\end{tabular}


Table 3. The Free Length of Vibrating Strings for Various Stringed Instruments

\begin{tabular}{|l|l|}
\hline Instrument & Free Length \\
\hline & mm $^{16-19}$ \\
\hline Violin & 328 \\
\hline Viola & $380^{*}$ \\
\hline Cello & 700 \\
\hline Bass & 1060 or $1100^{48}$ \\
\hline Guitar & 650 \\
\hline Mandolin & 350 \\
\hline *Violas are also $400,360,330 \mathrm{~mm}$ \\
\hline
\end{tabular}

Table 4. Important Materials Properties for Several String Materials

\begin{tabular}{|c|c|c|c|c|}
\hline & Density & $\begin{array}{l}\text { Tensile } \\
\text { Limit }\end{array}$ & $\mathbf{E}$ & Poisson's \\
\hline & $\mathrm{g} / \mathrm{cm}^{3}$ & MPa & GPa & Ratio \\
\hline Tungsten ${ }^{26}$ & 19.3 & 960 & 400 & 0.28 \\
\hline Silver $^{26}$ & 10.5 & $170-296$ & 74 & 0.37 \\
\hline Steel $^{21}$ & 7.85 & $2620-3000$ & 210 & 0.313 \\
\hline $\begin{array}{l}\text { Aluminum }{ }^{26,27} \\
\text { (Alloy 2024) }\end{array}$ & 2.77 & $185-470$ & 72.4 & 0.33 \\
\hline Gut $^{19}$ & $1.27^{48}$ & $241-310^{48}$ & $5.5-6.5$ & NA \\
\hline Silk $^{19}$ & 1.3 & $340-550$ & $5.0-6.0$ & 0.40 \\
\hline Nylon 26,27 & $1.12-1.14$ & $600-750$ & $4.5-5.5$ & 0.39 \\
\hline
\end{tabular}

Table 5. Specific Stiffness and the Speed of Sound

\begin{tabular}{|c|c|c|c|c|}
\hline & Density & $\mathbf{E}$ & E/ $/$ & $\begin{array}{l}V_{L} \\
\text { (approx.) }\end{array}$ \\
\hline & $\mathrm{g} / \mathrm{cm}^{3}$ & GPa & $\mathrm{m}^{2} / \mathrm{s}^{2} * 10^{6}$ & $\mathrm{~m} / \mathrm{s}$ \\
\hline Air & 0.0012 & & & 344 \\
\hline Tungsten $^{26}$ & 19.3 & 400 & 20.7 & 4550 \\
\hline Silver $^{26}$ & 10.5 & 74 & 7.05 & 2650 \\
\hline Steel $^{21}$ & 7.85 & 210 & 28.8 & 5170 \\
\hline $\begin{array}{l}\text { Aluminum }{ }^{26,27} \\
\text { (Alloy 2024) }\end{array}$ & 2.77 & 72.4 & 26.1 & 5100 \\
\hline Brass $70 / 30^{27}$ & 8.47 & 105 & 12.4 & 3500 \\
\hline Norway Spruce ${ }^{36}$ & 0.46 & 15 (long.) & 32 & 5700 \\
\hline Maple $^{40}$ & 0.80 & 17 (long.) & 21 & 4600 \\
\hline Clay $^{82}$ & 2.58 & 20.9 & 8 & 2800 \\
\hline Poplar ${ }^{27}$ & 0.38 & 11 & 28.9 & 5380 \\
\hline Gut $^{19}$ & $1.27^{48}$ & $5.5-6.5$ & $4.3-5.1$ & $1550-2260$ \\
\hline Silk $^{19}$ & 1.3 & $5.0-6.0$ & $3.8-4.6$ & $1960-2150$ \\
\hline Nylon ${ }^{26,27}$ & $1.12-1.14$ & $4.5-5.5$ & $4.0-4.9$ & $2000-2200$ \\
\hline
\end{tabular}


The design of a soundboard for any instrument is a difficult engineering problem in that the sound board should be as light as possible (flexible enough to move at many frequencies), but strong enough to resist the total string tension (which is substantial). For example, a harp soundboard will need to resist more than $6000 \mathrm{~N}^{31}$ of string tension and a violin must resist approximately $90 \mathrm{~N}$ of downward force as well as the $180-250 \mathrm{~N}$ of force in the direction of the strings $^{22-24}$. Considering violin tops of Stradivari and Guarneri were approximately $2-3 \mathrm{~mm}^{23}$ thick, and modern tops $3-5 \mathrm{~mm}$ thick, soundboards require careful engineering. Guitar soundboards and backs are usually $2.5 \mathrm{~mm}$, although they are more heavily braced than violins. In addition, scientifically minded makers and scientific researchers have found that $\mathrm{E}$, along and across the grain of the wood, the shear moduli, the density, and the velocity of sound in the wood to be the main factors that influence the tonal properties of the assembled violin ${ }^{23,24,26,28}$. In fact, some makers measure the density, and then the velocity of sound in the wood (with a Lucchi® Meter), before purchasing tone wood. Since the velocity of sound is proportional to the square root of E divided by the density, this is indeed consistent with materials engineering (see equation 1). The goal for good tone wood is to have as high of ratio as possible of the longitudinal E divided by the density. Joseph Curtin, a violin maker of the highest quality violins considers $0.4 \mathrm{~g} / \mathrm{cm}^{3}$ to be the highest acceptable density for spruce violin tops ${ }^{29}$. From Hutchins' work, "the desirable ratio of Young's modulus [E] along the grain to the Young's modulus [E] across the grain the spruce for violin tops is about 10:1, and in curly maple for violin backs is 5:3" ${ }^{28}$. Other literature sources place the ratio between 8 and $12^{32-35}$ for violin tops. The value that is stated most often for the $\mathrm{E}$ ratio for guitar tops is about 20 .

Using the design of musical soundboards is the best way I have found to introduce the complex topic of anisotropic materials to students in materials engineering. Soundboard design also is the time to introduce variability of materials properties, as wood is an especially variable material. The backs of violins and guitars are usually made from hardwoods (curly maple, for violins) and are chosen for both aesthetics and particular strength and stiffness characteristics. Soundboards for both instruments are usually made from spruce. Violin soundboards are made from Norway or Engleman spruce while guitar sound boards are made from Sitka spruce in the United States. Cedar and redwood may be used for soundboards of guitars to increase the sustain of the instrument. Long ago, makers chose naturally aged Norway spruce from high in the Alps for the finest violin sound boards. It seems what the makers were choosing, in fact, was a specific ratio of $E_{1} / E_{2}$ (as Hutchins later reported). Trees that have grown at high altitude have more uniform grain structures with little difference between spring and fall growth. Wood for soundboards and backs are made from quarter sawn wood which means the grain of the wood is parallel to the length of the instrument (see Figure 1). Since wood is an orthotropic material, it is an appropriate introduction to the differences between isotropic, orthotropic, and anisotropic materials. Table 6 shows the densities and $\mathrm{E}_{1}$ and $\mathrm{E}_{2}$ values for several sound board and back materials.

Additionally, the construction of guitars and violins can be used to help the students understand the conceptual differences between stiffness and mass in engineering design applications. While these are very interesting demonstrations, using them in class requires either a guitar or a violin in parts, although photos and figures of guitar and violin assemblies and bracing schemes are readily available of the web. Ready to assemble violin kits are available for less than $\$ 200$, 
while a guitar kit could cost as little as $\$ 100^{83-85}$. In fact, a ukulele kit that would serve to demonstrate many of these concepts is available for about $\$ 25^{83}$.

Table 6. Materials to Construct Violin and Guitar Sound Boards and Backs

\begin{tabular}{|c|c|c|c|}
\hline Material & Density & $\mathbf{E}_{1}$ & $\mathbf{E}_{2}$ \\
\hline & $\mathrm{g} / \mathrm{cm}^{3}$ & MPa & MPa \\
\hline Norway Spruce 36 & $\begin{array}{l}0.46 \\
{[ \pm .051]}\end{array}$ & $15000[ \pm 2100]$ & $760[ \pm 260]$ \\
\hline Sitka Spruce ${ }^{36}$ & $\begin{array}{l}0.46 \\
{[ \pm .050]}\end{array}$ & $13000[ \pm 2500]$ & $890[ \pm 240]$ \\
\hline Maple $^{40}$ & 0.80 & 17000 & 1564 \\
\hline $\begin{array}{l}\text { Brazilian Rosewood } \\
39\end{array}$ & 0.83 & 16000 & 2800 \\
\hline Indian Rosewood ${ }^{39}$ & 0.73 & 12375 & 2200 \\
\hline African Mahogany ${ }^{39}$ & 0.54 & 12000 & 930 \\
\hline
\end{tabular}

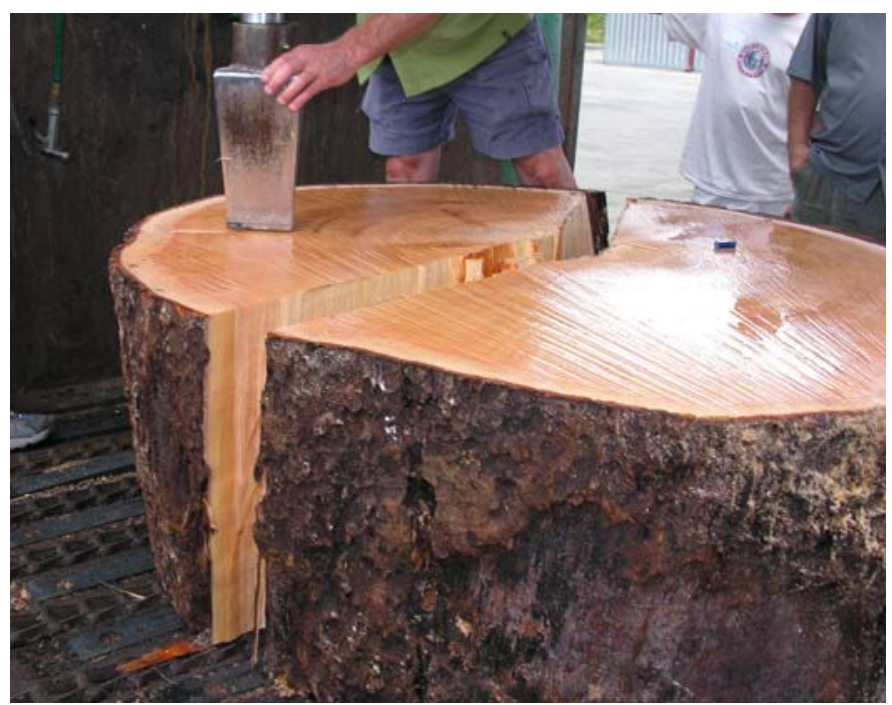

Figure 1. Splitting Engleman Spruce to Produce Quarter Sawn Sound Boards (Alumni Event, Pacific Tonewoods)

There are many different ways in which a guitar top is braced (stiffened), see Figure 2 for one example, while a violin top is stiffened only by a bass bar and a sound post. Figure 3 (left) shows the wooden bass bar that was added to a carbon fiber epoxy top that was part of a carbon fiber epoxy violin project completed as part of an independent study project by two students. One of the most interesting outcomes of using musical instrument design for materials engineering is the amount of interest of the students for follow-up Independent Study projects. Both of these figures are from such Independent Study projects. While it is always difficult to truly assess the changes one makes in the classroom to improved learning, it is much easier to judge the excitement of individual students who are truly involved in their own learning. These projects were proof of that excitement.

A starting point to help the students understand more about the basics of musical instrument design is similar to a more classical approach, but again presented and introduced in a new 
context. The basic constraints of engineering designs involve geometry and materials. Stress is independent of the materials used to construct the product, strain is not. To change the stress, either the load or the geometry must be changed.

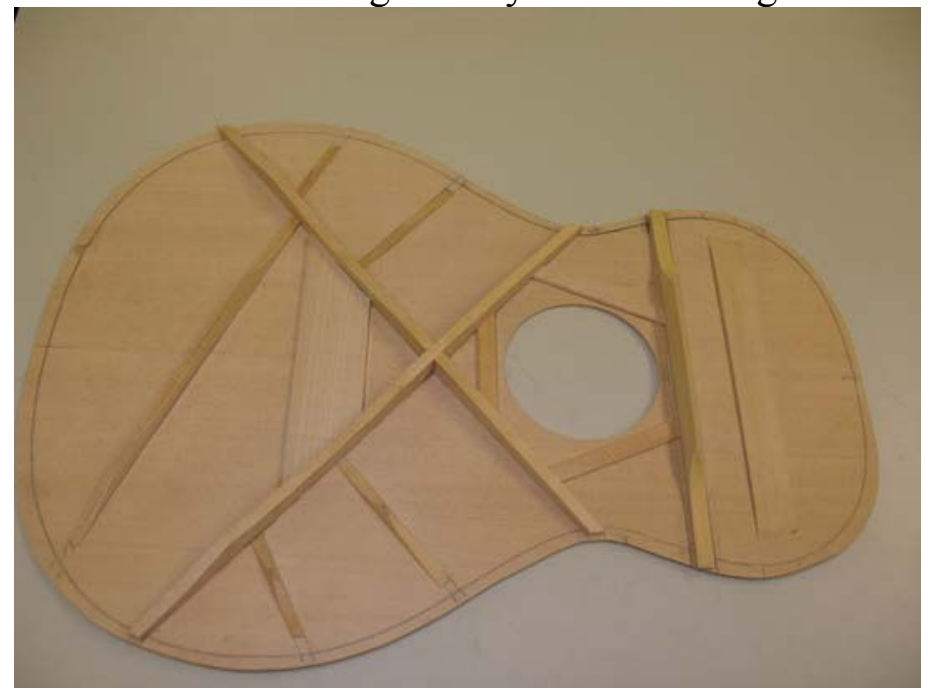

Figure 2. One Pattern Used to Stiffen a Guitar Sound Board (from Guitars Used to Evaluate Chladni patterns for an Independent Study project, Jesse Savage).

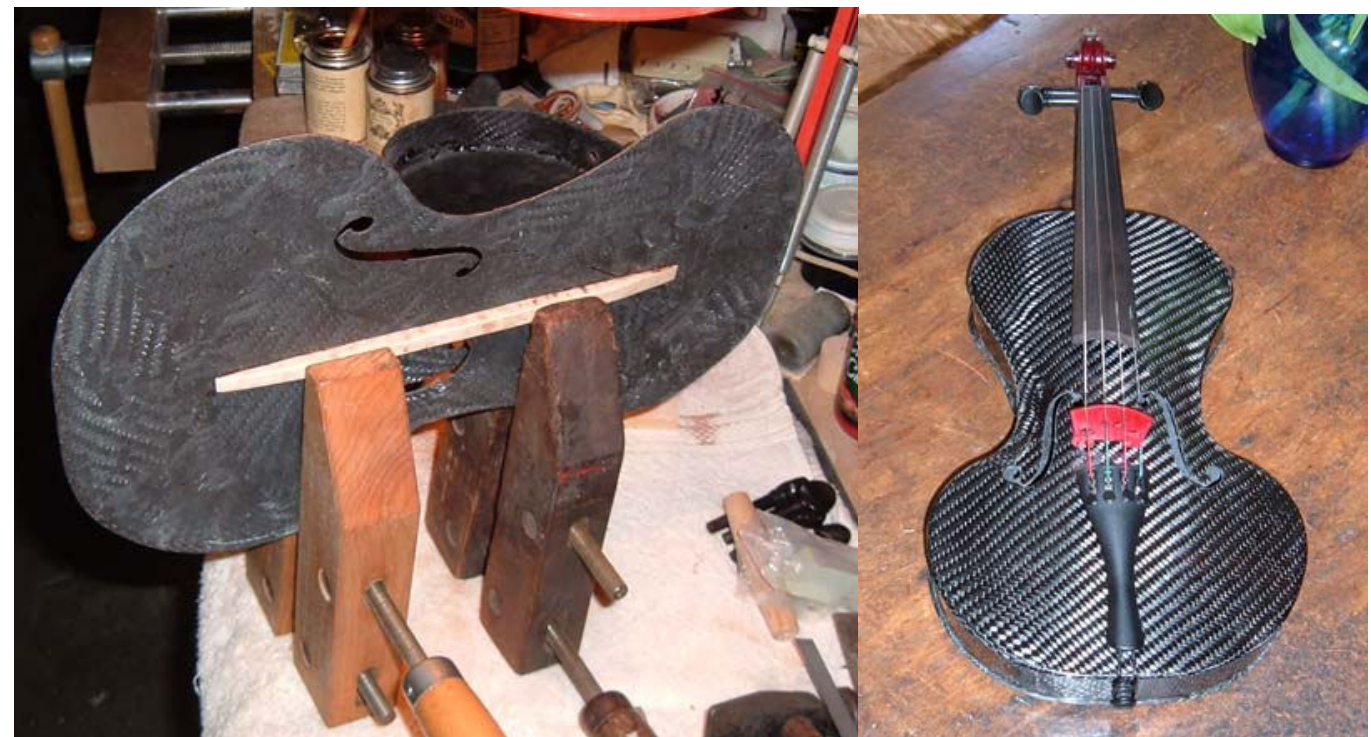

Figure 3. Adding a Wooden (spruce) Bass Bar to a Carbon Fiber Composite Violin Top (left) and the Assembled Carbon Fiber Composite (right) Violin (Bremer and Hart, Independent Research Project).

Often, in engineering, the load is not something that engineers may modify as it is a basic constraint. A cable must lift a load safely and include a safety factor, for example; and, a violin must sound like a violin. As with many engineering designs, the ratio of $E / \rho$ is crucial for soundboards, especially in the violin. Violin tops from Stradivari violins are much lighter than modern tops, even from high end makers, despite being made from lower density plates of Norway or Engleman spruce. A Stradivari violin top without a bass bar can weigh as little as 54 $\mathrm{g}$, which is more than 20 percent lighter than tops made by Joseph Curtin (a master American 
violin maker and MacArthur Fellow) ${ }^{41}$. Bass bars from the same Stradivari instruments weigh between 4 and $4.5 \mathrm{~g}^{41}$. The next logical step beyond simple engineering stiffening examples is the use of Chladni patterns and FEA animations to show the students the complex way in which stiffness, mass and geometry are important to engineering design. The FEA animations are not described in this paper. Since Chladni patterns have long been used in physics demonstrations, the equipment to produce them is widely available as are the plates (including the violin shaped flat plate ${ }^{86}$. A straight-forward method to produce them is described here, but the equipment can purchased relatively inexpensively $(\$ 500)$ or possibly borrowed from your Physics Department. Chladni patterns for guitars and violins are also readily available on the web.

Chladni patterns have been used by scientifically minded violin makers to tune their top and back plates since Hutchins work found relationships between certain tap tones ${ }^{23-24,35,41}$ that were related to important materials properties. When the plate resonates, large areas of the plate move about and the glitter bounces away from the vibrating areas and collects in regions of no motion. The frequency of any mode is determined by both stiffness (E) and the mass of the plate. Of course, the geometry also determines the Chladni patterns, but if the same geometry is used from plate to plate, then the effects of mass and $\mathrm{E}$ on the modes of vibrations are more visible. Modes 2 and 5 are most important to the design of a violin soundboard because they are directly related to the $\mathrm{E}$ of the plate across and along the grain of the top ${ }^{41-42}$. Recent work by Joseph Curtin showed that the spruce found in old Italian violin tops may be stiffer along the grain, and/or weaker across the grain than the current tone wood ${ }^{41}$. Again, introducing the conceptual ideas on how mass and stiffness are interrelated in engineering design, in a new and interesting context, interest and excite the students. Figure 4 shows example Chladni patterns of flat violin tops we made from different materials to demonstrate the difference materials make when the same geometry is used for the plate. Figure 5 shows Chladni patterns that were created as part of an Independent Study project where the student was investigating the changes in the Chladni patterns as the top was tuned (shaving the braces, see Figure 2) and the effect on the final body cavity. [A dxf file is available for the violin flat plate upon request.] We cut our plates from this file on a water jet cutter in our manufacturing lab. Note that although the patterns are memorable to review, the emphasis should be on the materials property reasons for the patterns. Since stiffness [E] is proportional to the square of the frequency, you can easily see the effect of even small differences in $\mathrm{E}$ in the Chladni patterns. Plate resonances are actually created by $\mathrm{E}$ and the mass (density) which cause standing waves to be formed in response to vibrations at discrete frequencies ${ }^{28}$. The patterns illustrate a number of significant points to the students. First, the geometry determines how the standing waves are set-up in the plates. The frequencies of the resonances are determined by the materials properties ( $E$ and $\rho$ ). Point out that the patterns of vibrating plates in certain vibrating modes are fixed by the geometry. However, the actual frequencies are determined by the material (see Figures 4 and 5) properties of the Elastic Constant and mass (density). For example, Curtin found that the frequency of mode 2 varies between 117 hertz and 150 hertz, while the mode 5 frequencies ranged between 304 hertz and 332 hertz ${ }^{41}$ for several old Italian violin tops made from spruce. A well designed violin top should have as high of $\mathrm{E} / \rho$ as possible.

There are three methods that can be used to produce Chladni patterns, and all can be used for demonstrations and research projects. The plate can be bowed with a violin bow (a cello bow for larger plates); it can be excited by a strong sound wave of a particular frequency; and it can be 
excited mechanically or electromechanically. Since spectrum analysis software packages can easily produce a sine wave of any needed frequency, the strong sound wave method was chosen at our university. Glitter and salt were found to produce excellent Chladni patterns, with glitter being more visible, but harder to clean up after the patterns are produced. You can create an acceptable Chladni pattern for thin plates (less than 1 or $2 \mathrm{~mm}$ ) with an inexpensive PC speaker (Altec Lansing®, model VS 2120 (\$30), for example). The front screen is removable, so it is easy to position the speaker underneath the plate. A better choice for the speaker which is still reasonably inexpensive is the Megawork ${ }^{\circledR}$ THX 2.1 250D system from Creative Labs $(\$ 150)$. The small size (a 3.5 inch driver) of the powerful satellite speakers, their high power (75 watts per speaker), their powerful subwoofer (150 watts), and their combined frequency response of 25 hertz to 20,000 hertz make the Megawork ${ }^{\circledR}$ system ideal for creating Chladni patterns. To create the pattern successfully, place the vibrating plates as close as you can to the speaker. Small pieces of foam should be used to hold the plate, but be sure to position them only beneath a node. Placing the foam under a vibrating section will dampen that vibration. You will have to experiment with the plates ahead of time to find the locations of the node for each frequency you will use. The Chladni patterns for the guitar plates and bodies were produced with a Behringer ${ }^{\circledR}$ ULTRATONE K1800FX 180W PA (\$230) and a CD player and CDs with the sine wave frequencies files in increments of 1 hertz.

A more comprehensive way to measure the response of musical instruments is to use a Frequency Response Function (FRF). In many ways, demonstrating the FRF of a violin or a guitar to your class is much easier than dealing with Chladni patterns and is very easy to do, assuming you have an inexpensive violin $(\$ 60)$ or a guitar $(\$ 100)$. To measure the FRF of a violin for a class demonstration is not as complex as what needs to be done for acoustic research on instruments. In order to measure the research FRF, the violin or guitar must be excited across its frequency range, the resulting sounds or motions must be measured, the input and output signals must be compared, and the room acoustics should be considered ${ }^{43}$. It is also true that a violin will radiate sound differently in different directions and that the characteristics will change with variables such as humidity and room sound parameters. However, for a class demonstration, a simple "snapshot" 45 of the instrument in question will satisfy the objective of the exercise, which is simply to stimulate a directed class discussion. In scientific violin research, a calibrated impact hammer (\$1000-\$2000) (see Figure 6) often supplies the input signal so that the input and output signals can be precisely compared. Impulse excitation methods deliver all the excitation frequencies all at once in the form of a blow ${ }^{45}$. In the classroom, a simple tap on the back of the instrument with a knuckle can provide a quite adequate input signal. In fact, instrument makers have long used these "tap" tones, their keen sense of hearing and their experience base to build fine instruments.

The microphone that was selected for these demonstrations is an inexpensive and affordable ultra-miniature, Electret type microphone from Radio Shack (model 33-301 - \$25). This microphone was suggested by Rodgers ${ }^{47}$ as an alternative to a very expensive measurement microphone. Since there are no precise measurements that are needed and the microphone has a relatively flat response curve in the necessary range, is small and portable, and is battery operated, it is a perfect instrument for use with a laptop in class. Its response curve is nearly flat to 6000 hertz which works well because flat the range is exactly what is needed for these demonstrations. 
Before the demonstration, place a soft piece of plastic foam underneath the strings to dampen their response during the experiment. Place the microphone described above near the outside, front of the instrument, start the acquire data in Adobe Audition ${ }^{\circledR}$ or a similar package such as Audioscope ${ }^{\circledR}$ and give the lower back of the instrument a sharp rap with your knuckle or tap it with a flick of your finger.

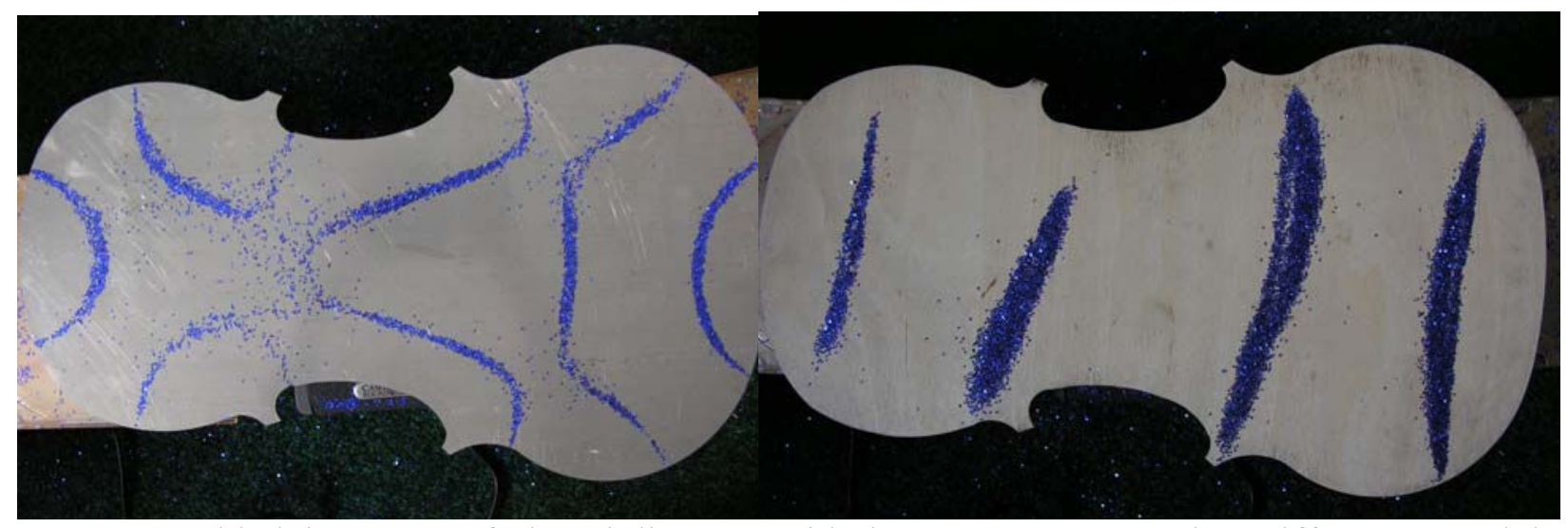

Figure 4. Chladni Patterns of Flat Violin Tops with the Same Geometry, but Different Materials (Aluminum on the left [829 Hertz] and Composite Wood Fiber Board on the right [290 Hertz])

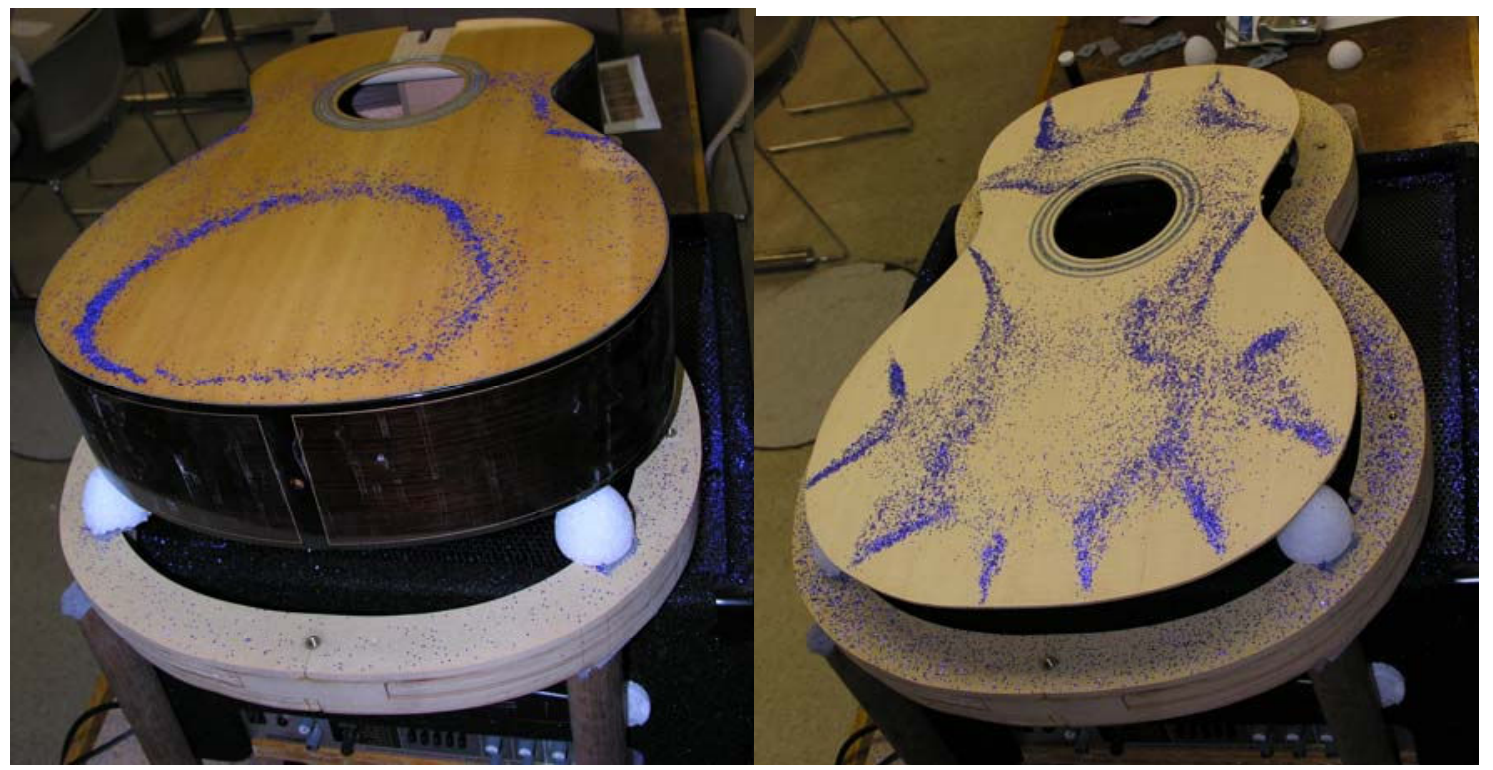

Figure 5. Chladni Pattern of a Guitar Body (left) and Top (right) Under Investigation (Jesse Savage, Independent Research Project)

Practice this ahead of time since the response does depend on the "tap". Repeat this several times, so that you can acquire more than one data set. Stop the data acquisition and complete a Fast Fourier Transform (FFT) on the decaying part of the signal. It is not particularly important which part of the decaying signal is selected. The Helmholtz (A0) main air resonance or f-hole resonance is around 270-290 hertz and is especially easy to find on the FFT graph (see Figure 7). Many individuals can also find this main air resonance by blowing across the f-hole. The students probably have blown across a bottle to find the Helmholtz resonance of a bottle, so this 
can be a lively and fun interaction with the students in class. It is easy (with a little practice) to find and measure A0 with a tap on the violin. The response from plucking the end of the fingerboard of the violin should yield a smaller peak just above or below the A0 air resonance ${ }^{46}$. The main body resonance, the B1 mode, is about 500-550 Hertz and appears precisely if the area around the bass-bar region is tapped ${ }^{46}$. Recall that the bass bar is a line constraint under the low note side of the bridge. Tapping other objects in the classroom can also be interesting for the students. Tap an object with something other than a knuckle, such as a key, and higher level frequencies are excited and the tap itself sounds different ${ }^{46}$. Note the A0 frequency (about 275 Hertz) and the B1 mode of a Chinese factory violin in Figure 7 (FFT results).

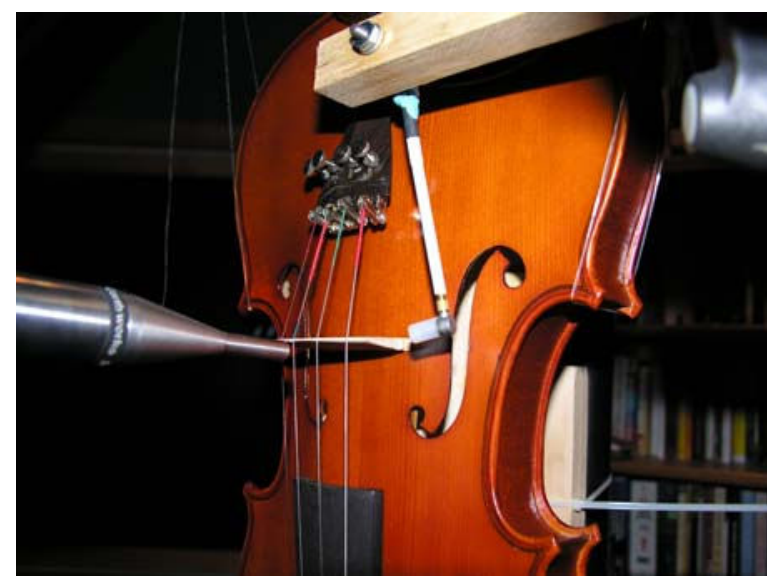

Figure 6. Measuring the Frequency Response of a Violin

The final interesting exercise to show the students is the difference between simply adding mass to an engineering system (the violin) and adding stiffness. The idea for this exercise comes totally from another noted American violin maker, Sam Zygmuntowicz, who first presented the "Gluey Violin" at the Violin Society of America's Acoustics Research Workshop in 2005. At that workshop, Sam placed small, very thin poplar [see Table 5] wood strips (1 mm or so) and glued them (with hot rosin) to a violin top and bottom to adjust the tone. The violin he used for the experiment was a specially modified Chinese factory instrument. He removed the top and decreased the thickness so it would be sensitive to small spot modifications to the stiffness of the top. As he reported at that conference, the sound was "frighteningly" sensitive to the glued on pieces of wood (spot increases in E). The idea is that you can increase $\mathrm{E}$ faster than you increase mass with these small pieces of glued on wood. Violin makers have long used globs of modeling clay [see Table 5] while they are final tuning the plates of their instruments, but doing so adds mass and not really much stiffness as the globs are not permanently affixed to the violin.

The demonstration described next is the one active experience that is difficult to transfer to other institutions. Although, it is NOT necessary to create a research violin to demonstrate the differences between adding mass and stiffness, it does require the use of a violin in white that has been set-up or the patience to remove the varnish from an inexpensive instrument that has already been set-up. The violin shown in Figure 8 is an inexpensive instrument (\$50) with its heavy varnish removed. Stripping the varnish is indeed messy and time consuming (about three hours total). The experiment itself is simple, add modeling clay gobs or thin strips of wood, measure the FRF and display the FFT or simply tap test or spring test the finger board. This particular demonstration is admittedly a lot of work. Another way to demonstrate these concepts 
would be to use FEA animations. While not described here, the students have responded positively to such FEA animations too.

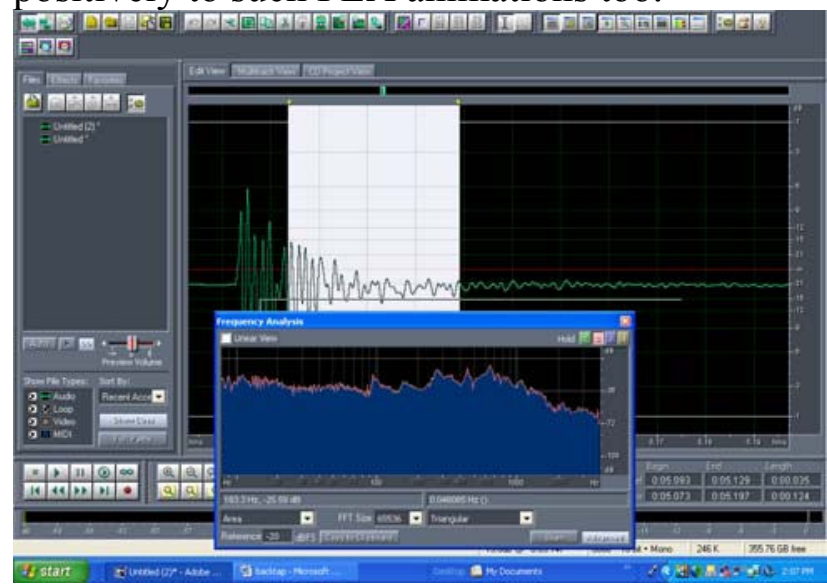

Figure 7. The Frequency Spectrum (FFT) from Tapping the Back of a Student Violin

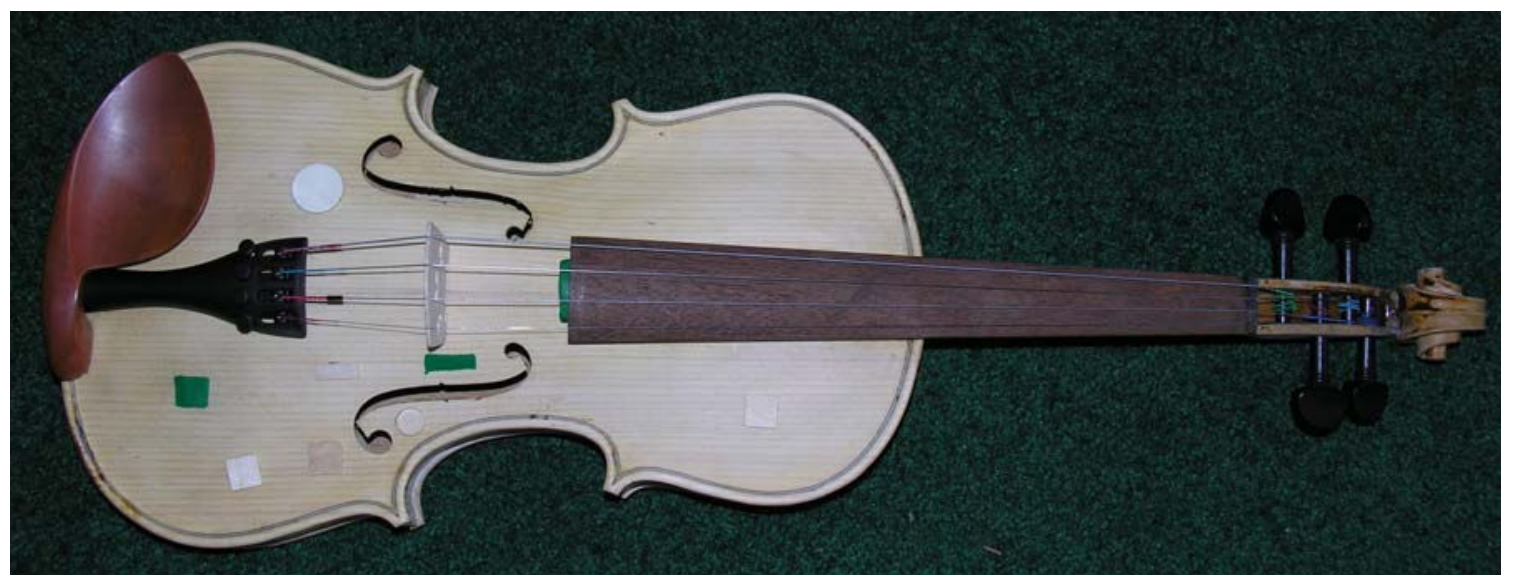

Figure 8. Violin to Show to the Difference between Adding Mass (green clay) and stiffness (spruce patches) [after the Gluey Violin, Sam Zygmuntowicz, VSA, Oberlin Workshop 2005]

\section{Assessment and Student Learning}

It is always difficult to measure with any degree of certainty improved student learning over relatively short periods of time with small sample sizes. However, it is known that if students are more engaged in their own learning, and if students are more interested in the subject, that learning is likely improved ${ }^{1-13}$. One measure of student engagement is how many times the students stay after class to learn something more about what was covered in class on any particular day. These informal interactions with students have increased significantly since the course has been transformed to an active, "learner - centered" format. Students have brought unusual instruments to me, and there are often discussions centered on new ideas for instrument materials in my office. One student made a CD of him playing two different acoustic guitars made from quite different materials (both of them borrowed) to compare tonal differences for himself (and he made $\mathrm{E} / \rho$ and other materials engineering calculations). It is not often that a student is so engaged in a course that they spontaneously do a mini-research project. Seven students have volunteered to work on undergraduate research projects in this area. Ten to fifteen percent of the students in the class write about some aspect of materials and music for their 
required research papers. This is only a three percentage points lower than the students who write about materials used in cars. The approach described here seems to reach out to a different and wider student population.

Perhaps the most surprising outcome of the active and conceptual learning modifications to the course was that the students are able to successfully complete a much more difficult design problem on the second mid-term and on the final exam. The students are given five or six materials with their materials properties (yield, density, elastic constant, Poisson's ratio, and cost) and a set of design criteria which might include minimizing multiple factors, such as deflection, cost, weight, or diameter change. Only $5-10 \%$ of the students do not successfully complete this challenging problem on the final exam. Before the modifications to this course, the students completed a straightforward design problem on the final at a $60 \%$ to $80 \%$ success rate. Since this problem is a good indicator for a number of important course objectives, this success is an important and meaningful improvement.

Table 7 shows a summary of whether there was improvement in Classical Test Scores (CTS) based upon all the changes made to the course. There was no attempt to separate the different effects from all the transformation components - concept questions, active learning exercises or case studies. However, particular concept areas could certainly be at least partially attributed to musical instrument design, while other certainly could not be attributable the changes described in this paper. Table 7 denotes those concept areas for which a case could be made that the focus on musical instrument design in the course contributed to the improvement in the scores. The measurable improvement threshold was approximately $10 \%$. The modified class sample size is about one hundred and thirty, so the sample size is small and thus the confidence level very low. Thus, the indicator is marked as probable or not observed. A maybe indicator shows much uncertainty in the improvement data.

Table 7. Improvement in Classic Test Scores from All Changes in the Course (advances partially attributed to musical instrument design/demos as noted)

\begin{tabular}{|l|c|c|}
\hline Concept Area & $\begin{array}{c}\text { Measurable } \\
\text { Improvement } \\
\text { CTS }\end{array}$ & $\begin{array}{c}\text { Partially Attributed to } \\
\text { Musical Component }\end{array}$ \\
\hline Bonding Energy \& Materials Prop. & Maybe & No \\
\hline Atomic Packing Factor & Probable & No \\
\hline Planar Density & Probable & No \\
\hline BCC/FCC/HCP & Probable & Yes \\
\hline Elastic Constant & Probable & No \\
\hline Dislocations & Not Observed & Yes \\
\hline Anisotropic Materials Properties & Probable & Yes \\
\hline Tensile Strength & Probable & No \\
\hline Elastic/Plastic Deformation & Probable & Yes \\
\hline Hardness & Not Observed & Yes \\
\hline Yield Strength & Probable & \\
\hline Design - Materials Selection & Probable & \\
\hline
\end{tabular}




\begin{tabular}{|l|c|c|}
\hline Safety Factor & Probable & Yes \\
\hline Precipitation Hardening & Probable & No \\
\hline Phase Diagrams, not steel & Not Observed & No \\
\hline Steel & Probable/Maybe & No \\
\hline Wear Resistance & Maybe & No \\
\hline Impact Loading & Maybe & No \\
\hline Materials Properties/Temperature & Probable & Maybe \\
\hline
\end{tabular}

\section{Conclusion}

The materials engineering aspects of musical instrument design have been integrated into our Introductory Materials Engineering course during the past several years. We have found that this approach does excite students about materials engineering and science. For example, students have completed numerous independent undergraduate research projects investigating "why" (from a materials engineering aspect) an instrument produces the sound it does and have made traditional instruments from new, advanced materials. Several students have also completed impromptu experiments on their own to help them understand the complex behaviors of materials in their own instruments. These short experiments ranged from changing guitar body materials to clarinet reed materials. The use of musical instrument engineering in class is part of a larger transformation of this course from a traditional lecture delivery format to an active, "learner centered" course. While we did indeed invest a great deal of time and energy thus far to create this comprehensive transformation, we believe that the students enjoy materials engineering to a higher degree, are more involved in their own learning, and score somewhat higher, as a group, on certain classical examination questions. Unfortunately, our sample sizes are still small, but we will continue to build an assessment data base for this course as we continue to teach and modify this course. Because the initial assessment data is at least encouraging, we plan to continue making changes to the course that encourage active involvement of the students in their own learning. Since it is a rare student who has no contact with or interest in music, the transformations described here seem to have contributed to the course in that the students immediately embrace the context and appear to be more comfortable moving on to classical problems. Perhaps the most surprising outcome of the active and conceptual learning modifications to the course was that the students are able to successfully complete a much more difficult design problem by the end of the term. The students are more satisfied with the course and rate the instructor higher with regard to understanding their level of learning. It seems the students appreciate not only the knowledge gained from the active class exercises, but they also appreciate the effort and investment made in these exercises and activities on their behalf.

\section{Bibliography}

1. National Research Council Commission on Behavioral and Social Sciences and Education, How People Learn: Brain, Mind, Experience and School, Commission of Behavioral and Social Sciences and Education, Washington, DC, National Academy Press, 2000 (on-line free access, http://books.nap.edu/books $/ 0309070368 / \mathrm{html} /$ ).

2. Bonwell, C. and Eison, J., "Active Learning: Creating Excitement in the Classroom, ASHE-ERIC Higher Education Report Number 1", The George Washington University, School of Education and Human Development, Washington, DC, 1991. 
3. http://www.udel.edu/pbl/.

4. Felder, R. M., and R. Brent, "Navigating the Bumpy Road to Student-Centered Instruction", College Teaching, 1996, pp. 43-47.

5. Hake, R. R., "Interactive-Engagement vs. Traditional Methods: A Six-Thousand-Student Survey of Mechanics Test Data for Introductory Physics Courses", American Journal of Physics, Vol. 66, No. 1, pp. 64-74, 1998.

6. Raju and Sanker, "Teaching Real-World Issues through Case Studies", Journal of Engineering Education, Vol. 88, No. 4, pp. 501-508, 1999.

7. Smith, C., "Student Written Engineering Cases, International Journal of Engineering Education, Vol. 8, No. 6, pp. 442-445, 1992.

8. Richards L. G., Gorman M., Scherer, W. T., and Landel, R., "Promoting Active Learning with Cases and Instructional Modules", Journal of Engineering Education, Vol. 84, No. 4, pp. 375-381, 1995.

9. Mazur, E., Peer Instruction: A User's Manual, Prentice Hall, New Jersey, 1997.

10. Ellis, G. W., Mikic B., and Rudnitsky, A. R., "Getting the Big Picture in Engineering: Using Narratives and

Conceptual Maps", Proceedings of the 2003 American Society for Engineering Education Annual Conference and Exposition, Nashville, TN, 2003.

11. Ellis, Scordilis, and Cooke, "New Pedagogical Approaches in Engineering Mechanics Yield Increased Student Understanding, Confidence and Commitment", Frontiers in Education Conference, 2003.

12. Huba, M.E. and Freed, J. E., Learner-Centered Assessment on College Campuses: Shifting the Focus from

Teaching to Learning, Allyn and Bacon, Boston, MA, 2000.

13. Bloom, B.S., Taxonomy of Educational Objectives: The Classification of Educational Goals: Handbook I, Cognitive Domain, Longmans, Green, 1956.

14. Kitto, K. L., "Perspectives from the Classroom - Developing Effective Concept Questions and Collaborative Learning for an Introductory Materials Course", ASEE Frontiers in Education Conference, 2006, session S4H-1.

15. Kitto, K. L., "Materials Science for the Twenty-First Century - Active and Engaged Students", Frontiers in Education conference, ASEE Frontiers in Education Conference, 2005, session F4C-4.

16. http://www.daddariobowed.com

17. http://www.supersensitive.com

18. http://www.daddario.com

19. Jansson, Erik, Acoustics for Violin and Guitar Makers, Chapter IV, Properties of the Violin and the Guitar String, Fourth Edition, 2002, http://www.speech.kth.se/music/acviguit4/part4.pdf .

20. Fletcher, H, "Normal Vibrations of a Stiff Piano String", Journal Acoustics Society of America, 36: 203-2008, 1964.

21. ASTM 228, ASTM Standards, 2004, Volume 01.03, page 19.

22. http://www.josephcurtinstudios.com/news/tech/journal_vsa/principles.htm

23. Hutchins, C., October 1981, "The Acoustics of Violin Plates," Scientific American, pp. 172-186.

24. Hutchins, C., November 1962, "The Physics of Violins," Scientific American, pp. 78-93.

25. Loen, J., Thickness Graduation Maps, 2004.

26. Callister, W. D. Jr., Fundamentals of Materials Science and Engineering: An Integrated Approach, John Wiley and Sons, $2^{\text {nd }}$ edition, 2004.

27. http://www.matweb.com

28. Hutchins, C., October 1981, “The Acoustics of Violin Plates,” Scientific American, pp. 172-186.

29. Public Comment, J. Curtin, VSA, November 2004.

30. Hutchins, C., March 1995, "Measurable Characteristics of Violin Family Instruments in Relation to the Sound of a High-Quality Violin," MRS Bulletin, XX, pp. 29-31.

31. http://www.acoustics.org/press/149th/waltham.html

32. French, M., and Bissinger, G., January/February 2001, "Testing of Acoustic Stringed Musical Instruments -

An Introduction," Experimental Techniques, pp. 40-43.

33. French, M., and Bissinger, G., March/April 2001, "Testing of Acoustic Stringed Musical Instruments - Part 2, "Experimental Techniques, pp. 34-37.

34. http://www.phys.unsw.edu.au/music

35. Hutchins, C., and Benade, A., editors, Research Papers in Violin Acoustics 1975-1993, Acoustical Society of America, 2, pp. 765-905.

36. Haines, D., 2000 “The Essential Mechanical Properties of Wood Prepared for Musical Instruments," Journal Catgut Acoustical Society Journal, 4, No. 2, pp. 20-32.

37. Bucur, V., 1995, Acoustics of Wood, CRC Press, New York. 
38. Duennwald, H., May 1991, "Deduction of Objective Quality Parameters on Old and New Violins," Journal of the Catgut Acoustical Society, 1, No. 7, pp. 1-4. 32.

39. Haines, D., 1979, “On Musical Instrument Wood," Journal Catgut Acoustical Society Journal, 31, pp. 23-32.

40. Knott , George, A., "Research Papers in Violin Acoustics”, pp. 513.

41. Curtin, Joseph, "Tap Routine", The Strad, October 2006, pp. 48 - 54.

42. http://www.phys.unsw.edu.au/jw/chladni.html

43. Curtin, J., and Schleske, M., July 2004, "Domestic Bliss,” The Strad, pp. 696-700.

44. Barker, J., "Violin Making, a Practical Guide", The Crowood Press, Ramsbury, Malborough, Wiltshire, 2001.

45. Curtin, J., and Schleske, M., January 2004, “A World Apart?” The Strad, pp. 16-20.

46. Curtin, J., and Schleske, M., April 2004, "Man and the Machine," The Strad, pp. 352-356.

47. Rodgers, O., May 1998, "Nodal Line Seeker," Journal Catgut Acoustical Society, 3, No. 5, pp. 41-44.

48. Pickering, N., "The Bowed String", Amereon LTD, New York, 1991.

49. Beament, J., "The Violin Explained", Oxford University Press, 1997.

50. Pickering, Norman, "A New Type of String for Bowed Instruments", Journal of the Violin Society of America, Vol. 15, Issue 1, 1997, pp. 25-44.

51. Besnainou, Charles, "From Wood Mechanical Measurements to Composite Materials for Musical Instruments", Materials Research Society Bulletin, March 1995,Vol. XX, No. 3, pp. 34-36.

52. Maillot, Bernard, "How to Anticipate Future Changes in Strings", Journal of the Violin Society of America, Vol. 18, Issue 2, 2003, pp. 203-220.

53. Urgela and Saldner, "Determination of Violin Tone Wood Using Electronic Holography", Photomechanics, SPIE, Vol. 2342, 1994, 166-172.

54. Cavanaugh, John, Cavanaugh Jim and Patterson, Caryn, "Strings: the Third Element", Journal of the Violin Society of America, Vol. 18, Issue 2, 2003, pp. 61-69.

55. Giordano, N., "The Physics of Vibrating Strings", Computers in Physics, Vol. 12, No. 2, March/April 1998, pp. 138-145.

56. Jansson, Erik, V., "Experiments with the Violin String and Bridge", Applied Acoustics, Vol. 30, 1990, pp. 133-146.

57. http://www.educatorscorner.com/student_resources/aae/guitarx_eng

58. Sali and Kopac, "Measuring a Frequency Response of a Guitar", Proceedings of SPIE, Vol. 4062, 2000, pp. 1375-1379.

59. Pickering, N. "A Holistic View of Violin Acoustics", Journal of the Violin Society of America, Vol. 17, Issue 1, 2000, pp. 29-53.

60. Rogers, Oliver and Anderson, Pamela, "From Acoustics Lab to Violin: Engineering and Violin Making Perspectives", The Journal of the Violin Society of America, Vol. 18, No. 1, 2002, pp. 119-146.

61. Pickering, Norman, "Problems in String Making", Catgut Acoustical Society of America, Vol. 2, No. 3, 1993, pp. 1-4.

62. Pickering, Norman, "String Testing", Journal of the Violin Society of America, Vol. 10, Issue 2, 1990, pp. 107-132.

63. Richardson, R., "The Guitar: Its Past, Present and Future”, Acoustics Bulletin, May/June 1994, pp. 5-9.

64. Duennwald, H., "Deduction of Objective Quality Parameters on Old and New Violins, Journal of the Catgut Acoustical Society, Vol. 1, No. 7, May 1991, pp. 1-4.

65. Pickering, Norman, "Strings and Metallurgy", Catgut Acoustical Society", Vol. 3, No. 4, 1997, pp. 24-29.

66. Loen, Jeffrey, "Strings for Violin, Viola, and Cello: A Survey of What Elite Players Use", Journal of the Catgut Acoustical Society, Vol. 4, Issue 6, 2002, pp. 17-21.

67. Gorrill, W.S. and Pickering, N., "Strings: Facts and Fallacies", Journal of the Violin Society of America, Vol. 8, No. 1, 1986, pp. 27-40.

68. Boullosa, Ricardo, R., "Vibration Measurements in the Classical Guitar", Applied Acoustics, Vol. 62, (2002), pp. 311-322.

69. http://www.montana.gibson.com and http://www.martinguitar.com

70. Caldersmith, G., "Designing a Guitar Family", Applied Acoustics, Vol. 46, 1995, pp. 3-17.

71. Dann, Elias, "The Second Revolution in the History of the Violin: A Twentieth Century Phenomenon", Journal of the Violin Society of America, Vol. 4, Issue 1, 1977, pp. 48-57.

72. Rossing, T., Moore, F., and Wheeler, P., "The Science of Sound”, Third Edition, Addison Wesley, 2001.

73. Fletcher, N. and Rossing, T., "The Physics of Musical Instruments", Springer, Second Edition, 2005.

74. Benade, A., "Fundamentals of Musical Acoustics", Second Edition, Dover Publications, 1990.

75. Benade, A., "Horns, Strings, and Harmony", Dover Publications, 1992. 
76. Hopkin, B.," Musical Instrument Design”, See Sharp Press, 2000.

77. Bell, D., November 2002, "Modal Analysis for the Working Luthier", Journal Catgut Acoustical Society, 4, No. 6, pp. 9-16.

78. Schleske, M., November 2002, "Empirical Tools in Contemporary Violinmaking Part II, Psycho Acoustical Analysis and Use of Acoustical Tools, Journal Catgut Acoustical Society, 4, No. 6, pp. 45-64.

79. Buchater, B., and Regh, J., 2001 "Spectrafoo: A New Tool for Acoustical Analysis," Journal of the Violin Society of America, 17, Issue 2, pp. 107-122.

80. Strobel, H., 2001, “Violin Making Step by Step”, Second Edition, HenryStrobel.com.

81. Strobel, H., 2003, "The Art and Method of the Violin Maker", Third Edition, HenryStrobel.com.

82. http://www-odp.tamu.edu/publications/204 SR/103/103 t1.htm

83. http://www.grizzly.com/products/searchresults.aspx?q=instrument+kit

84. http://www.stewmac.com/shop/Kits/Violin_Kits/Violin_Kits.html

85. http://www.woodcraft.com/family.aspx?FamilyID $=5505$

86. http://store.pasco.com/pascostore/showdetl.cfm?\&DID=9\&Product ID $=54943 \&$ Detail $=1$ 